\title{
Avian Influenza: Hong Kong Outbreak ${ }^{1}$
}

\author{
G. D. Butcher, DVM, Ph.D., R. D. Miles, Ph.D., and A. H. Nilipour²
}

\section{Chronology of Events Related to the Hong Kong Avian Influenza Outbreak}

In February through April of 1997, a massive die-off of poultry was reported in the Guangdong province of Mainland China. The die-off was caused by an avian influenza H5N1 virus. Chickens produced in this area were transported and sold in live poultry markets in Hong Kong.

Poultry are sold in Hong Kong almost exclusively "on the foot" in crowded markets. This is traditional in Hong Kong and in other Asian markets. Even during the crisis, consumers resisted purchasing processed, frozen poultry products.

In late March through May 1997, a die-off of poultry in three small poultry farms in Hong Kong due to an acute, highly virulent disease was reported. The causative disease agent was confirmed as avian influenza H5N1. In numerous newspaper reports, a "leading" American virologist irresponsibly referred to this $\mathrm{H} 5 \mathrm{~N} 1$ avian influenza virus as the "Chicken Ebola!" This virologist described the disease process in chickens as "spreading swiftly, attacking all the cells in the infected bird's body and nearly always fatal," catching the attention of the media. It must be remembered that the human Ebola virus outbreak in Africa, which had only recently stunned and frightened the world, was still fresh in the minds of many. In reality, avian influenza virus has scant similarity to Ebola. This scientist, in an attempt to grab headlines and recognition, did a major disservice to all.

In May 1997, a 3-year-old boy died of "complications" from H5N1 avian influenza (Reyes Syndrome). This strain was previously only believed to infect birds.

This was the first documented case of human infection with an avian influenza virus.

In November 1997, a 2-year-old boy developed flu-like symptoms and recovered. He was shown to be carrying antibodies against $\mathrm{H} 5 \mathrm{~N} 1$ influenza virus. This H5N1 virus was different enough to suggest it came from a different source than the initial H5N1 virus.

1. This document is VM138, one of a series of the Veterinary Medicine-Large Animal Clinical Sciences Department, Florida Cooperative Extension Service, Institute of Food and Agricultural Sciences, University of Florida. Original publication date June 12, 2002, reviewed and revised May 16, 2005. Visit the EDIS Web Site at http://edis.ifas.ufl.edu.

2. Gary D. Butcher, DVM, Ph.D., Diplomate, American College of Poultry Veterinarians, University of Florida College of Veterinary Medicine, Gainesville, FL., Richard D. Miles, Ph.D., Professor, Poultry Nutritionist, Department of Dairy and Poultry Sciences, Amir H. Nilipour, PhD, Director of Investigation and Quality Assurance, Grupo Melo, S.A., Panama, Republic of Panama

The Institute of Food and Agricultural Sciences (IFAS) is an Equal Opportunity Institution authorized to provide research, educational information and other services only to individuals and institutions that function with non-discrimination with respect to race, creed, color, religion, age, disability, sex, sexual orientation, marital status, national origin, political opinions or affiliations. U.S. Department of Agriculture, Cooperative Extension Service, University of Florida, IFAS, Florida A. \& M. University Cooperative Extension Program, and Boards of County Commissioners Cooperating. Larry Arrington, Dean 
In early December 1997, three more deaths occurred as a result of infection with influenza strain $\mathrm{H} 5 \mathrm{~N} 1$. The victims were 60,54 , and 13 years.

Several hospital staff attending affected patients and members of the family of the 13-year-old who died in early December developed flu-like symptoms and were placed under observation. This triggered a panic in the area, as it suggested human-to-human transmission was possible. It was later shown that neither hospital employees nor family members were infected with the H5N1 influenza virus, but they were infected with one of various other human respiratory diseases circulating in the area.

In mid-December, five more positive cases of infection with $\mathrm{H} 5 \mathrm{~N} 1$ were confirmed in people 37 , $24,5,3$, and 2 years of age. The 2- and 3-year-olds were cousins of a 5-year-old who became sick three days earlier. This again pointed to possible human-to-human transmission or possible contact with the same infected chickens. All these individuals recovered.

A state of panic enveloped Hong Kong. A news release dated January 4, 1998, noted that -"Tens of thousands of people with runny noses are rushing to hospitals, thousands of pet birds have been abandoned by owners, tourists have been warned to avoid Hong Kong." A lack of understanding of the epizootiology of the disease and sensationalist news media reports left people confused and frightened.

Human cases in summary: one case in May 1997; five cases in November, 1997; 12 cases in December, 1997. No new clinical cases were identified after December 28, 1997. Eight human mortalities had been confirmed. Age range of clinically affected: 1 to 60 years of age. All patients older than 13 years of age had severe clinical disease with $57 \%$ mortality, children younger than 5 years had mild symptoms with one death from Reyes Syndrome complications.

Extensive serologic studies conducted revealed a seroconversion level of $2 \%$ in "suspect people." Suspects were categorized as follows: contact with confirmed infected people (2\%), poultry plant workers (17\%), neighbors of confirmed infected people $(1 \%)$, family members of confirmed infected people $(0 \%)$. Note: this is describing only seroconversion, not clinical disease. These findings suggested that many people were being exposed and infected with avian influenza H5N1, but were not developing clinical disease. Of interest also was that only 7 of the 18 cases of human disease had a history of possible recent direct or indirect contact with poultry.

The Hong Kong Department of Agriculture and Fisheries ordered a complete slaughter of all chickens in Hong Kong on December 29, 1997. Over the following 3 days, 1.3 million chickens were slaughtered. Of interest was that in live poultry markets surveyed, $10 \%$ or more of the poultry were shown to be shedding H5N1 virus. However, these birds were clinically normal. This caused considerable confusion and could not be explained as this virus had earlier decimated poultry flocks, causing up to $100 \%$ mortality. All ducks, geese, quail, and caged pigeons were also killed. Pet bird owners were dumping off unwanted pets at shelters. Exports of chicken from Mainland China were temporarily halted. The depopulation process was a disaster from a logistical perspective. The news media documented numerous cases where animals such as stray dogs had entered the dumpsites and were consuming and carrying off carcasses, and wild birds also had access to the carcasses.

Following a period after the complete depopulation of poultry from the island (December 29,1997 ) and during which no additional human cases were reported, live chicken was again permitted on February 7, 1998 to be imported from Mainland China and sold in Hong Kong markets. Farms permitted to export chickens were licensed and monitored by the Mainland Animal and Plant Quarantine Services to ensure they were not exposed to $\mathrm{H} 5 \mathrm{~N} 1$ avian influenza virus.

\section{Animal-to-Human Transmission of Influenza}

Historically, influenza viruses are believed to cycle from birds to swine and from swine to people. Unique among animals, swine carry viral receptors for both human and avian influenza viruses. However, birds and people do not carry compatible receptors to permit a direct sharing of common influenza viruses. 
If swine are infected with both a human- and a bird-origin influenza virus, these viruses can hybridize (cross and share genetic information) and possibly create a more lethal human virus or create a more lethal bird virus. These processes occur on a yearly basis and are responsible for most human influenza viruses that emerge. The current H5N1 influenza is unique in that it appears to have been transmitted directly from birds to humans, without the usual swine intermediary.

The last two human influenza pandemics are believed to have originated in China, where there are large numbers of farm-raised poultry and swine in close proximity to a large, concentrated human population. This culture provides the conditions ideally suited for the development of the new influenza viruses.

\section{Could H5N1 Avian Influenza Virus Cause a Pandemic in Humans?}

To date, there have been 18 confirmed human cases and 8 human deaths caused by H5N1 influenza.

To cause a pandemic, the virus must easily and efficiently spread from person to person. The H5N1 influenza virus was demonstrated genetically to be avian in nature with no evidence of re-assortment with the human influenza virus genes, i.e. a pure avian virus. Influenza viruses are known to readily mutate, as evidenced by the great number of $\mathrm{H}$ and $\mathrm{N}$ types identified. Many in the scientific community have expressed concern that the longer the virus is transmitted among the human population, the greater the possibility that it will mutate and become highly adapted for humans, and thus spread more efficiently.

Extensive studies to date have not conclusively demonstrated the mode of transmission or variables that affect virulence in the human population. During serologic investigations of suspect individuals, seropositives were identified in the human population with no history of clinical disease. A small number of people infected became severely ill and died soon after onset of clinical disease. An interesting finding was that the very young appeared resistant. Only two out of 11 children under 18 years of age died when disease occurred, and the 3-year-old patient died from complications related to the treatment, not from primary disease. In the 7 patients over 18 years of age, 6 died ( $88 \%$ mortality!).

Of considerable interest was the fact that poultry industry workers in Hong Kong were not getting sick and there were no reports in China of human illness. To date, there are still no reported cases of avian influenza (H5N1) in humans in Mainland China. There is no explanation yet for these phenomena.

Preliminary studies suggest that bird-to-human transmission is likely, but very inefficient, and that human-to-human transmission is rare if it is possible at all. The highest incidence of seroconversion was in poultry plant workers exposed to infected poultry.

If an epidemic in the human population occurred, treatment would be with an anti-viral drug called amantadine and vaccination. Currently available vaccines for this year's human influenza viruses include the inactivated type A H1N1 and H3N2, neither of which would provide protection against $\mathrm{H} 5 \mathrm{~N} 1$. A recently developed H5N1 vaccine is available, produced by Protein Sciences Corporation, a Biotechnology Company. Human trials for this vaccine are in progress. This company, using modern biotechnology practices, was able to produce a suitable vaccine in only a couple months.

Presently, avian influenza outbreaks are being reported in other areas of the world in commercial poultry-Australia H7N4; USA (Pennsylvania) H7N2; Mexico H7N2; Italy H5N. This level of worldwide infection is within the normal range, but the anomaly in Hong Kong has attracted attention. Investigators have not yet been able to determine the original source of this $\mathrm{H} 5 \mathrm{~N} 1$ virus. A possible source to consider is migratory birds. Continued surveying of these birds is being conducted, as it is possible they will continue to cycle the virus and potentially reintroduce the disease into the human and/or poultry populations along their migratory routes. Another possible source to consider is swine. 


\section{Actions by Government/Regulatory Bodies}

Politics and economics, rather than science, directed many decisions made during the disease in Hong Kong. The decision to kill off poultry in Hong Kong was political and economical. To date, there is still no conclusive evidence of bird-to-human transmission and no evidence of human-to-human transmission. Studies are ongoing, and, in the future, answers to these questions may be available. These answers will allow for implementation of practical control measures. 